\title{
ANALISIS PEMODELAN 3 DIMENSI BANGUNAN BERSEJARAH MENGGUNAKAN FOTOGRAMETRI JARAK DEKAT \\ (STUDI KASUS: MAUSOLEUM DINGER, JAWA TIMUR)
}

\author{
Dean Ahmed Falahesa ${ }^{1}$, Agung Budi Cahyono ${ }^{2}$, Husnul Hidayat ${ }^{3}$ \\ 1,2,3 Departemen Teknik Geomatika, FTSLK-ITS, Kampus ITS Sukolilo, Surabaya, 60111, Indonesia \\ e-mail: ${ }^{1}$ deanahmed19@gmail.com, ${ }^{2}$ agungbudicahyo@gmail.com, ${ }^{3}$ hidayathusnul@yahoo.com
}

\begin{abstract}
Abstrak
Mausoleum Dinger merupakan makam dengan bentuk bangunan bergaya arsitektur Belanda yang dulunya digunakan untuk menyimpan jenazah seseorang berkebangsaan Belanda bernama Jan Dinger dan telah ditetapkan sebagai bangunan cagar budaya oleh Pemerintah Kota Batu. Makam ini dengan statusnya sebagai cagar budaya harus dilakukan upaya untuk menjaga dan melestarikan bentuk aslinya sesuai Undang-Undang No. 11 Tahun 2010 tentang Cagar Budaya. Pada penelitian ini, dilakukan upaya pelestarian dengan pendokumentasian makam berupa model rekonstruksi 3D. kegiatan pendokumentasian dilakukan dengan pengakuisisian data serta pembuatan model 3D dari Mausoleum Dinger baik dari luar (eksterior) maupun dari dalam (interior) mengingat makam ini berbentuk bangunan yang berarti memiliki ruang di dalamnya, menggunakan metode fotogrametri jarak dekat. Model 3D yang telah terbentuk kemudian dilakukan analisa mengenai tingkat akurasi dari akuisisi data dan proses pemodelan makam. Dilakukan juga analisa mengenai tingkat kesesuaian dalam kelas orde 4 (LoD4) karena pemodelan 3D sudah mencakup bagian dalam (interior) dari bangunan makam. Hasil dari akuisisi data berupa foto eksterior dan foto interior bangunan Mausoleum Dinger, dan hasil analisa dari nilai RMSE yang kurang dari $0.2 \mathrm{~m}$, sehingga memenuhi kriteria Level of Detail 4 (LOD 4).
\end{abstract}

Kata Kunci : Cagar Budaya, Fotogrametri Jarak Dekat, LOD4, Makam Dinger, Model 3D.

\begin{abstract}
The Dinger Mausoleum is a tomb with a Dutch architectural style that was used to store the body of a Dutch national named Jan Dinger and has been designated as a cultural heritage building by the Batu City Government. This tomb with its status as a cultural heritage must be tried to preserve and preserve its original form in accordance with Law No. 11 of 2010 concerning Cultural Heritage. In this study, conservation efforts were carried out by documenting the tomb in the form of a $3 D$ reconstruction model. Documentation activities are carried out by acquiring data and creating $3 D$ models from Dinger Mausoleums both from the outside (exterior) and from inside (interior) considering that the tomb is in the form of a building which means it has space inside, using close-range photogrammetric methods. The 3D model that has been formed is then analyzed for the level of accuracy of the data acquisition and tomb modeling process. An analysis of the level of suitability in the 4th order class (LoD4) is also carried out because 3D modeling includes the interior of the tomb building. The results of the data acquisition took the form of exterior photos and photos of the interior of the Dinger Mausoleum, and the results of the analysis of the RMSE values were less than $0.2 \mathrm{~m}$, thus fulfilling the Level of Detail 4 criteria (LOD 4).
\end{abstract}

Keywords : Close Range Photogrammetry, Cultural Heritage, LoD4, Mausoleum of Dinger, 3D Model 


\section{PENDAHULUAN}

Mausoleum atau makam Dinger terletak di Dusun Wonorejo, Desa Tulungrejo, Kecamatan Bumiaji, Kota Batu, Jawa Timur. Makam ini merupakan makam dari sesorang berkebangsaan Belanda bernama Jan Dinger, hal ini diketahui dari pahatan yang terletak di muka bangunan yang bertuliskan 'Graf Familie Dinger'. Di sebelah kanan dan kiri pahatan tersebut terdapat pahatan lain yang bertuliskan 'Anno' yang berarti tahun dalam Bahasa Belanda dan '1917' yang menandakan tahun berdirinya makam ini yang juga telah ditetapkan sebagai cagar budaya oleh Pemerintah Kota Batu.

Cagar budaya adalah warisan budaya bersifat kebendaan berupa Benda Cagar Budaya, bangunan Cagar Budaya, Struktur Cagar Budaya, Situs Cagar Budaya, dan Kawasan Cagar Budaya di darat dan/atau di air yang perlu dilestarikan keberadaannya karena memiliki nilai penting bagi sejarah, ilmu pengetahuan, pendidikan, agama, dan/atau kebudayaan melalui proses penetapan (Mikhail, dkk, 2001). Walaupun telah ditetapkan sebagai cagar budaya, namun bangunan ini tampak terlupakan dan kurang terjaga dengan banyaknya sampah yang dibuang di sekitar makam serta bentuk keseluruhan makam yang telah banyak berubah menjadi areal perkebunan. Mausoleum Dinger telah kehilangan fungsi utamanya karena sudah tidak ada lagi jenazah yang ada di dalamnya. Namun sebagai bangunan cagar budaya, makam Dinger ini harus dipertahankan dari kerusakan yang mungkin timbul kedepannya (Pemerintah Indonesia, 2010). Salah satu cara untuk mempertahankannya adalah dengan cara melakukan pendokumentasian. Pelestarian Cagar Budaya harus didukung oleh kegiatan pendokumentasian sebelum dilakukan kegiatan yang dapat menyebabkan terjadinya perubahan keasliannya (Pemerintah Indonesia, 2010).

Rekonstruksi 3D adalah proses merekam bentuk suatu objek sekaligus membentuk struktur objek tersebut. Bentuk objek diinterpretasikan dalam koordinat spasial (titik-titik objek) yang diperoleh secara langsung (sensor aktif) maupun tidak langsung (sensor pasif) sehingga luaran akhir dari proses ini berupa visualisasi 3D. Untuk keperluan praktis, hasil dari rekonstruksi 3D digunakan dalam arsitektur dan teknik sipil untuk mendesain rancangan rekonstruksi bangunan (Permana, 2016).

Salah satu metode untuk rekonstruksi 3D adalah teknologi fotogrametri jarak dekat (close range photogrammetry) yang merupakan teknik pengukuran objek (2D atau 3D) dari hasil visualisasi data, seperti fotografi (foto), citra, kamera CCD, dan sensor radiasi (Rashidi, dkk, 2013). Agar membentuk visualisasi objek 3D maka pengguna (photogrammetry engineer) harus mengambil banyak foto dari berbagai sisi dan sudut objek secara manual sekaligus menggabungkannya untuk memperoleh visualisasi objek 3D tersebut. Sehingga, untuk memperoleh pendekatan kualitas resolusi dari hasil visualisasi 3D yang baik membutuhkan waktu pengumpulan data yang lama serta keahlian photogrammetry engineer selama proses pengolahan data spasial berlangsung Stone \& Cheok, 2001).

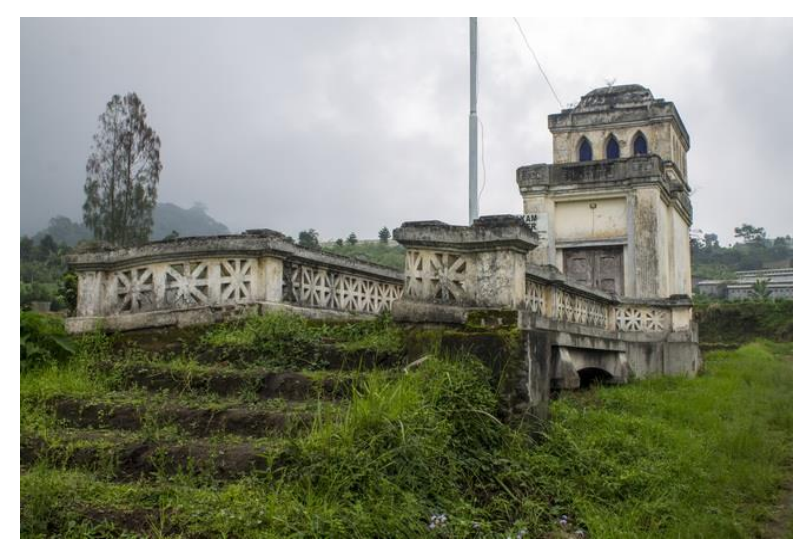

Gambar 1. Mausoleum Dinger

Pada penelitian ini, dilakukan akuisisi data serta pembuatan model 3D eksterior dan interior Mausoleum Dinger. Fotogrametri digunakan pada penelitian ini dengan tujuan untuk dapat menggapai dan mengambil foto struktur bagian atas dari Mausoleum Dinger dengan bantuan wahana UAV sebagai salah satu media pengambilan gambarnya. Penelitian ini juga menganalisa nilai RMSE dari model 3D baik dari sisi eksterior maupun interior makam. Dengan analisa tersebut diharapkan dapat menghasilkan dokumentasi berupa model 3D yang memiliki tingkat akurasi yang tinggi sehingga dapat dijadikan acuan dalam melakukan pelestarian di masa yang akan datang. 


\section{METODOLOGI PENELITIAN}

\section{Data dan Peralatan}

Berikut adalah data yang dibutuhkan dalam penelitian ini:

- Foto udara Mausoleum Dinger yang diakuisisi menggunakan Unmanned Aerial Vehicle (UAV) DJI Phantom 4 Pro.

- Foto tersteris eksterior dan interior Mausoleum Dinger yang diakuisisi dengan mengguanakan kamera Canon EOS 600D dan Nikon D3200.

- Koordinat titik kontrol Mausoleum Dinger.

- Spesifikasi kamera Canon EOS 600D dan Nikon D3200.

- Parameter internal kamera Canon EOS 600D dan Nikon D3200.

Peralatan yang dibutuhkan dalam penelitian ini dibagi menjadi perangkat keras dan perangkat lunak, meliputi:

a. Hardware: Wahana Dji Phantom 4, Kamera Nikon 3200D dan Canon EOS 600D, Total Station (TS) Reflectorless Hi Target ZTS 320R, 2 set Receiver GPS Geodetik Topcon HiperPro, Roll Meter, penggaris, dan bidang kalibrasi.

b. Software: ArcMap 10.6.1 Lisensi ITS, perangkat lunak pengolah parameter internal kamera, Topcon Tools (Demo mode), Microsurvey CAD 2019 (Demo Mode) dan perangkat lunak pengolah data foto.

\section{Lokasi Penelitian}

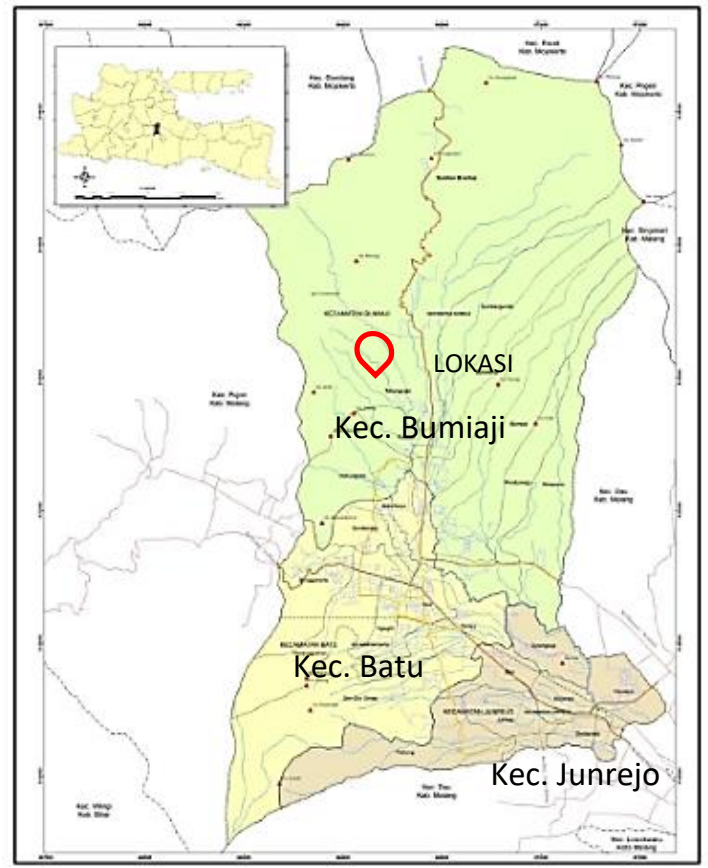

Gambar 2. Lokasi Penelitian (PemKot Batu, 2010)
Lokasi dalam penelitian ini berada di Dusun Wonorejo, Desa Tulungrejo, Kecamatan Bumiaji, Kota Batu, Jawa Timur. Secara geografis Mausoleum Dinger terletak di $7^{\circ} 47^{\prime} 51^{\prime \prime}$ LS dan $112^{\circ} 31^{\prime} 19.45^{\prime \prime}$ BT.

\section{Metodologi}

Adapun tahapan akuisisi dan pengolahan data dalam penelitian ini adalah sebagai berikut:

a. Pengukuran titik kontrol GCP, ICP

Penentuan letak titik kontrol yang akan diukur menggunakan GPS Geodetik direncanakan terlebih dahulu bersamaan dengan penempelan marker pada makam yang kemudian akan dijadikan sebagai GCP. Sedangkan ICP akan diukur pada setiap sudut bangunan tanpa marker. Baik GCP atau ICP akan diukur menggunakan Total Station Reflectorless dari setiap titik kontrol.

b. Pengambilan Foto Mausoleum Dinger Pengambilan foto makam dilakukan dalam dua tahap. Tahap pertama yaitu tahap pemotretan udara menggunakan wahana UAV DJI Phantom 4 Pro, pada tahap ini juga dilakukan foto udara guna membuat peta orthophoto sekitar makam. Tahap kedua adalah tahap pemotretan terestris menggunakan Kamera Nikon 3200D dan Canon EOS 600D, pada tahap ini dilakukan pemotretan dari sisi eksterior dan interior makam

c. Kalibrasi Kamera

Bidang kalibrasi di foto menggunakan kamera Nikon 3200D dan Canon EOS 600D dari 9 arah yang berbeda yang kemudian hasil dari pemotretan bidang kalibrasi akan selanjutnya diolah menggunakan perangkat lunak pengolah parameter internal kamera.

d. Pengolahan data foto

Model 3D dan peta orthophoto dihasilkan pada tahap ini menggabungkan foto dari wahana UAV dan 2 kamera lainnya. Adapun diagram alir pemodelan 3D adalah sebagai berikut:

\section{HASIL DAN PEMBAHASAN}

\section{Kalibrasi Kamera}

Hasil kalibrasi kamera in-laboratory precalibration seperti berikut. 


\begin{tabular}{ccc}
\hline \multicolumn{3}{c}{ Tabel 1. Hasil Kalibrasi } \\
\hline \multirow{2}{*}{ IOP } & \multicolumn{2}{c}{ Nilai } \\
\cline { 2 - 3 } & Nikon 3200D & Canon 600D \\
\hline$f$ & $5.53052006 \mathrm{~mm}$ & $7.02680238 \mathrm{~mm}$ \\
$\mathrm{X}_{0}$ & $2.27223569 \mathrm{~mm}$ & $2.58668998 \mathrm{~mm}$ \\
Yo & $1.45016914 \mathrm{~mm}$ & $1.74950286 \mathrm{~mm}$ \\
K1 & -0.06047 & -0.12615 \\
K2 & 0.02233 & 0.37117 \\
K3 & 0,00000 & 0.00000 \\
P1 & 0.00006 & 0.00121 \\
P3 & 0.00033 & -0.00255 \\
\hline
\end{tabular}

Dari hasil kalibrasi kamera didapatkan nilai IOP yang kemudian digunakan untuk proses pemodelan 3D Mausoleum Dinger.

\section{Hasil Pengukuran Titik Kontrol}

Titik kontrol pada penelitian ini berjumlah 4, dengan 1 titik sebagai base dan 3 lainnya sebagai titik kontrol objek. Titik kontrol diukur menggunakan GPS Geodetik dengan metode radial dan lama pengukuran 1 jam. Berikut adalah baseline yang terbentuk pada pengukuran titik kontol.

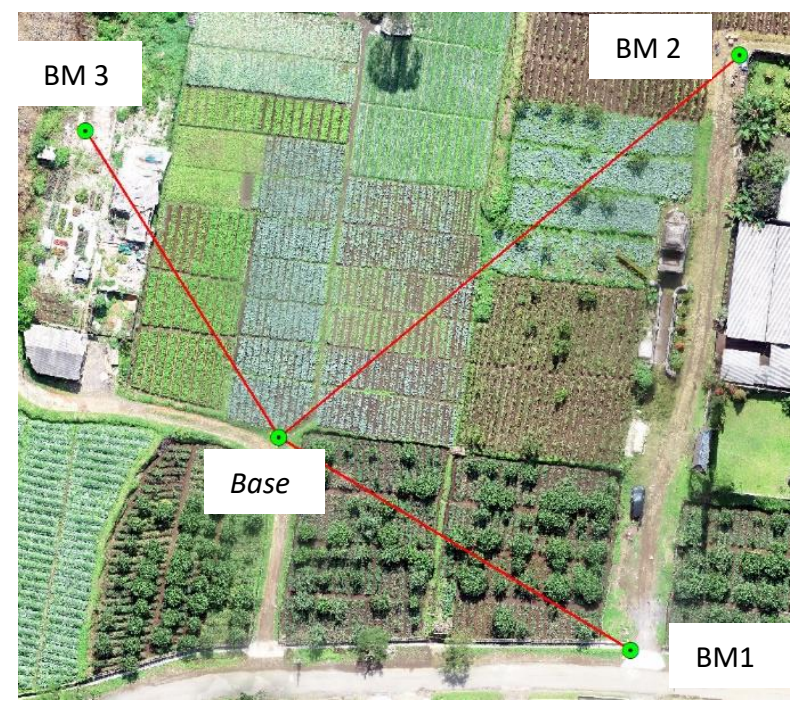

Gambar 3. Baseline Titik Kontrol

Berikut adalah nilai RMSE setiap titik setelah melalui proses pengolahan menggunakan Topcon Tools (Demo Mode) beserta nilai koordinat yang didapat.
Tabel 2.

Hasil Koordinat Titik Kontrol

\begin{tabular}{cccc}
\hline $\begin{array}{c}\text { Nama } \\
\text { Titik }\end{array}$ & Timur $(\mathrm{m})$ & Utara $(\mathrm{m})$ & $\begin{array}{c}\text { Ketinggian } \\
(\mathrm{m})\end{array}$ \\
\hline Base & 667778.817 & 9137762.489 & 1347.750 \\
BM1 & 667826.655 & 9137733.896 & 1347.086 \\
BM2 & 667841.565 & 9137813.853 & 1350.828 \\
BM3 & 667752.506 & 9137803.610 & 1351.351
\end{tabular}

Hasil koordinat di atas memiliki nilai RMSE pada tiap baseline seperti berikut.

Tabel 3. RMSE Titik Kontrol

\begin{tabular}{ccc}
\hline Nama Titik & RMS Horizontal $(\mathrm{m})$ & RMS Vertikal $(\mathrm{m})$ \\
\hline Base-BM1 & 0.001 & 0.002 \\
Base-BM2 & 0.002 & 0.003 \\
Base-BM3 & 0.001 & 0.001 \\
\hline
\end{tabular}

GCP dan ICP diperlukan untuk menganalisa nilai kesalahan posisi dan ukuran dalam sebuah model 3D objek. Adapun hasil koordinat GCP dan ICP dengan jumlah total sebanyak 36 titik (16 GCP dan 22 ICP) pada bangunan Mausoleum Dinger adalah sebagai berikut.

Tabel 4.

Hasil Koordinat GCP pada Bangunan

\begin{tabular}{ccccc}
\hline No. & $\begin{array}{c}\text { Nama } \\
\text { titik }\end{array}$ & Northing $(m)$ & Easting $(m)$ & $\begin{array}{c}\text { Elevasi } \\
(\mathrm{m})\end{array}$ \\
\hline 1 & GCP1 & 9137793.092 & 667833.128 & 1352.342 \\
2 & GCP2 & 9137792.316 & 667834.199 & 1352.509 \\
3 & GCP3 & 9137787.45 & 667834.021 & 1352.384 \\
4 & GCP4 & 9137784.585 & 667833.656 & 1352.345 \\
5 & GCP5 & 9137792.612 & 667831.882 & 1351.823 \\
6 & GCP6 & 9137782.778 & 667834.393 & 1351.225 \\
7 & GCP7 & 9137770.569 & 667832.766 & 1352.895 \\
8 & GCP8 & 9137771.235 & 667827.883 & 1352.804 \\
9 & GCP9 & 9137776.845 & 667830.315 & 1353.046 \\
10 & GCP10 & 9137776.637 & 667831.826 & 1353.067 \\
11 & GCP15 & 9137783.713 & 667830.669 & 1354.353 \\
12 & GCP13 & 9137784.93 & 667830.976 & 1354.29 \\
13 & GCP14 & 9137785.285 & 667832.111 & 1351.847 \\
14 & GCP18 & 9137789.472 & 667832.658 & 1353.314 \\
15 & GCP16 & 9137789.746 & 667832.032 & 1354.215 \\
16 & GCP17 & 9137789.603 & 667833.091 & 1354.247 \\
\hline
\end{tabular}




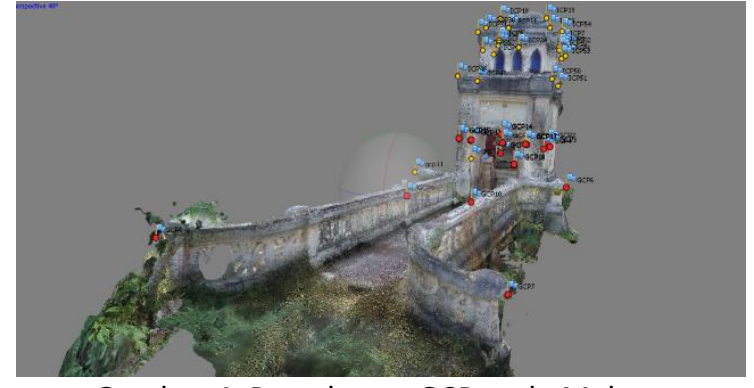

Gambar 4. Persebaran GCP pada Makam

Tabel 5. Hasil Koordinat ICP pada Bangunan

\begin{tabular}{ccccc}
\hline No. & $\begin{array}{c}\text { Nama } \\
\text { titik }\end{array}$ & Northing $(m)$ & Easting $(m)$ & $\begin{array}{c}\text { Elevasi } \\
(\mathrm{m})\end{array}$ \\
\hline 1 & ICP1 & 9137791.232 & 667834.546 & 1356.509 \\
2 & ICP2 & 9137791.245 & 667834.54 & 1356.848 \\
3 & ICP4 & 9137791.68 & 667831.208 & 1356.479 \\
4 & ICP5 & 9137791.331 & 667831.458 & 1356.918 \\
5 & ICP6 & 9137791.233 & 667831.414 & 1357.054 \\
6 & ICP7 & 9137790.873 & 667834.204 & 1357.093 \\
7 & ICP8 & 9137790.897 & 667834.212 & 1356.96 \\
8 & ICP9 & 9137790.457 & 667833.686 & 1357.554 \\
9 & ICP11 & 9137790.74 & 667831.836 & 1357.542 \\
10 & ICP18 & 9137788.58 & 667831.535 & 1357.544 \\
11 & ICP19 & 9137788.312 & 667833.444 & 1357.554 \\
12 & ICP24 & 9137787.79 & 667832.406 & 1356.281 \\
13 & ICP30 & 9137788.14 & 667830.964 & 1357.085 \\
14 & ICP31 & 9137787.838 & 667830.69 & 1356.876 \\
15 & ICP35 & 9137788.58 & 667830.88 & 1356.267 \\
16 & ICP47 & 9137787.865 & 667830.801 & 1354.864 \\
17 & ICP48 & 9137784.867 & 667830.274 & 1354.765 \\
18 & ICP50 & 9137784.45 & 667833.719 & 1354.704 \\
19 & ICP51 & 9137787.29 & 667834.113 & 1354.789 \\
20 & ICP52 & 9137788.167 & 667834.063 & 1356.293 \\
21 & ICP53 & 9137790.35 & 667834.334 & 1356.279 \\
22 & ICP54 & 9137787.317 & 667834.062 & 1356.862 \\
\hline & & & &
\end{tabular}

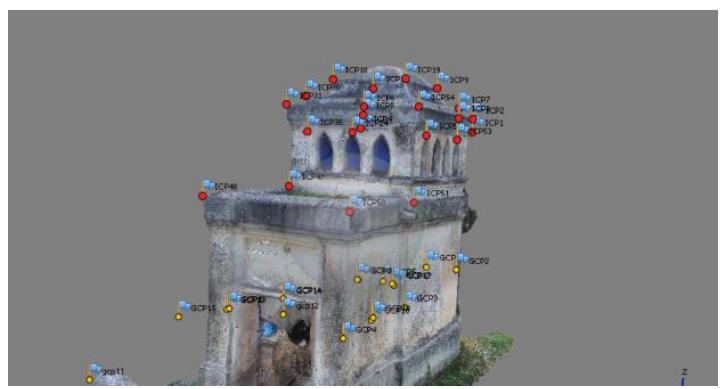

Gambar 5. Persebaran ICP pada Makam

\section{Model 3D}

1. Foto Objek

Foto objek yang digunakan dalam pengolahan ini sebanyak 814 foto dengan 2 tahap pengambilan gambar, tahap pengambilan gambar eksterior dan interioi bangunan makam. Foto bagian eksterior makam berjumlah 500 foto dan bagian interior makam berjumlah 314 foto. Pengambilan gambar dilakukan dengan 3 Kamera yaitu Canon 600D, Nikon 3200D, dan Kamera pada wahana DJI Phantom 4 Pro. Berikut sampel foto objek Mausoleum Dinger beserta sampel persebaran marker-nya.

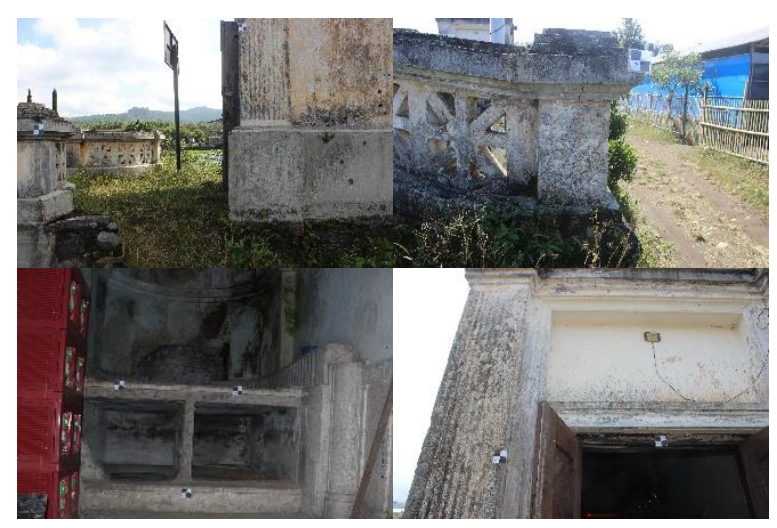

Gambar 6. Sampel Pengambilan Foto Objek (kiri-kanan, atas-bawah): Eksterior (Nikon 3200D), Eksterior (DJ Phantom), Eksterior (Canon 600D), Interior.

\section{Posisi Kamera}

Posisi kamera pada penelitian ini tersebar baik pada bagian luar (eksterior) hingga bagian dalam (interior) makam. Pengambilan bagian eksterior makam dibagi menjadi dua bagian yaitu bagian struktur bawah makam yang dipotret menggunakan kamera non-metrik dikombinasikan dengan kamera dari wahana UAV. Sedangkan untuk bagian interior makam hanya dipotret menggunakan kamera nonmetrik dengan jarak kamera dengan dinding atau struktur diusahakan seragam saat mengambil gambar. Berikut ilustrasi posisi kamera.

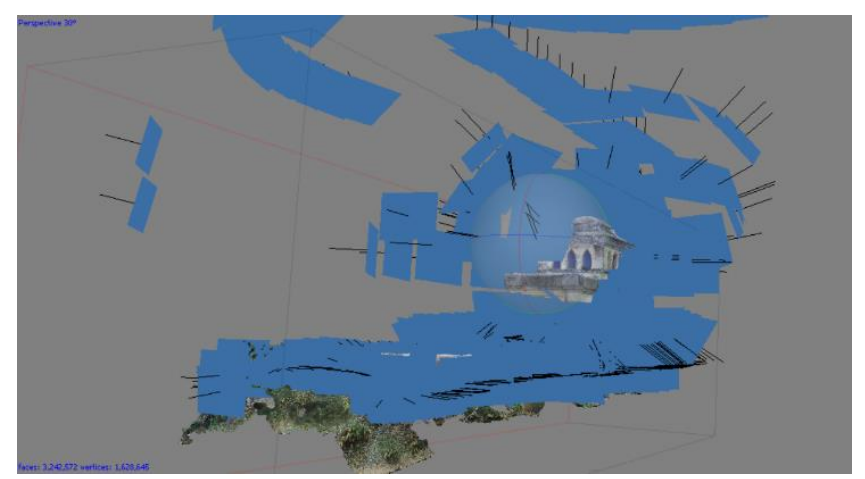

Gambar 7. Posisi Pengambilan Foto Eksterior Makam 


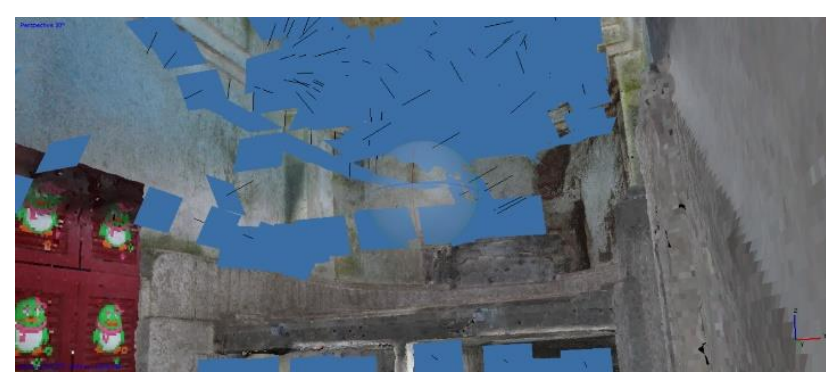

Gambar 8. Posisi Pengambilan Gambar Interior Makam

\section{Alignment Photo}

Proses Alignment Photo pada penelitian ini dilakukan pada tingkat medium baik untuk eksterior dan interior. Menghasilkan 169.295 titik untuk eksterior dan 122.018 titik untuk interior. Titik -titik tersebut disebut dengan Sparse Cloud. Pada tahap ini Model 3D makam sudah terlihat bentuknya namun masih berupa titik-titik yang renggang. Berikut hasil Sparse Cloud dari proses Alignment Photo.

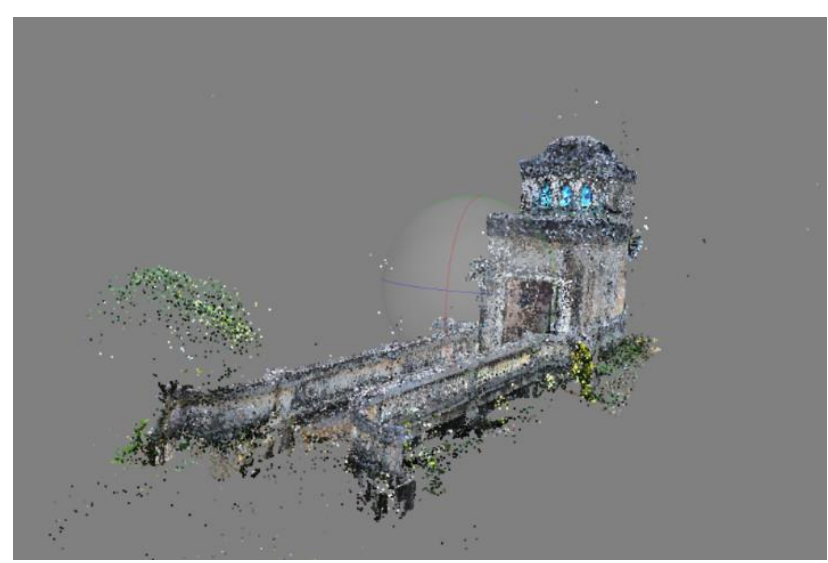

Gambar 9. Hasil Alignment Photo

4. Build Dense Cloud.

Proses Build Dense Cloud pada penelitian ini dilakukan guna merapatkan titik-titik Sparse Cloud pada proses sebelumnya. Dilakukan pada tingkat medium untuk eksterior dan high untuk interior. Menghasilkan 11. 4012.624 titik untuk eksterior dan 37.505.977 titik untuk interior. Berikut hasil Build Dense Cloud.

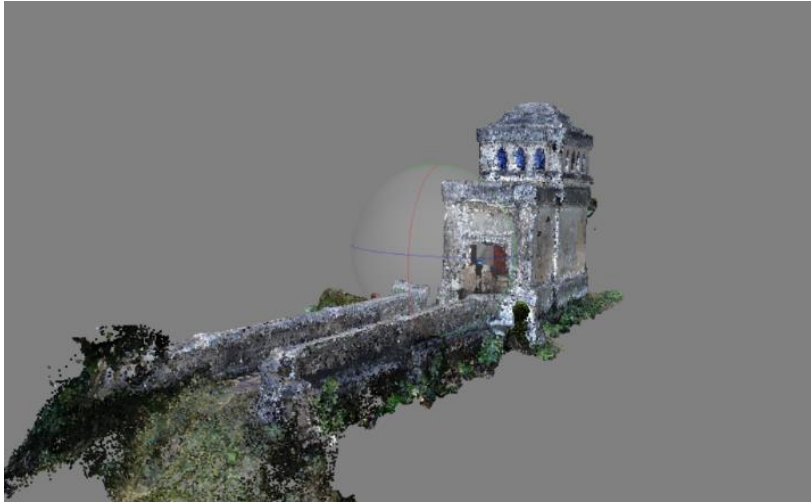

Gambar 10. Hasil Build Dense Cloud

\section{Build Mesh}

Proses Build Mesh pada penelitian ini dilakukan untuk membuat jaring-jarlng segitiga (faces) dari titik-titik Dense Cloud. Proses ini dilakukan pada tingkat medium dan menghasilkan 3.242.572 faces. Pada tahap ini detail dan struktur dari model sudah terbentuk seutuhnya namun belum terdapat warna atau tekstur sesuai objek aslinya. Berikut hasil Bulid Mesh.

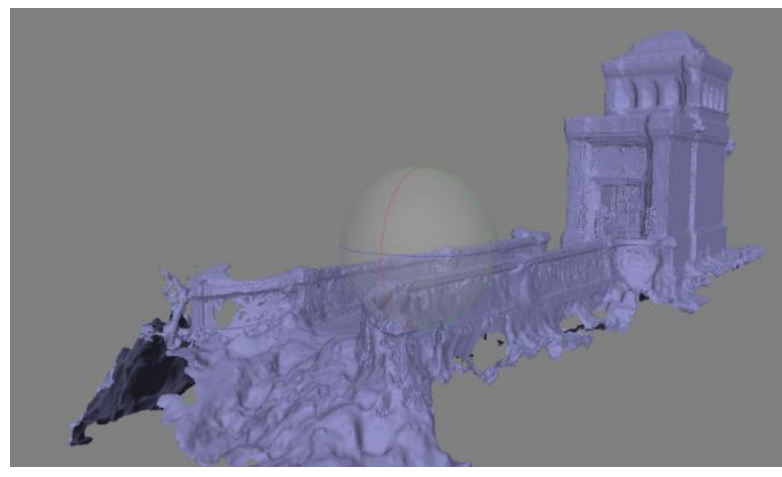

Gambar 11. Hasil Build Mesh

6. Model 3D Mausoleum Dinger

Setelah Model 3D berupa Mesh terbentuk dilakukan pemberian tekstur (texturing) atau pemberian warna pada Mesh sehingga model terlihat seperti penampakan objek aslinya. Model 3D Mausoleum Dinger yang dihasilkan pada penelitian ini terbagi menjadi 2 bagian yaitu model Eksterior dan Interior. Berikut adalah Hasil akhir Model 3D. 


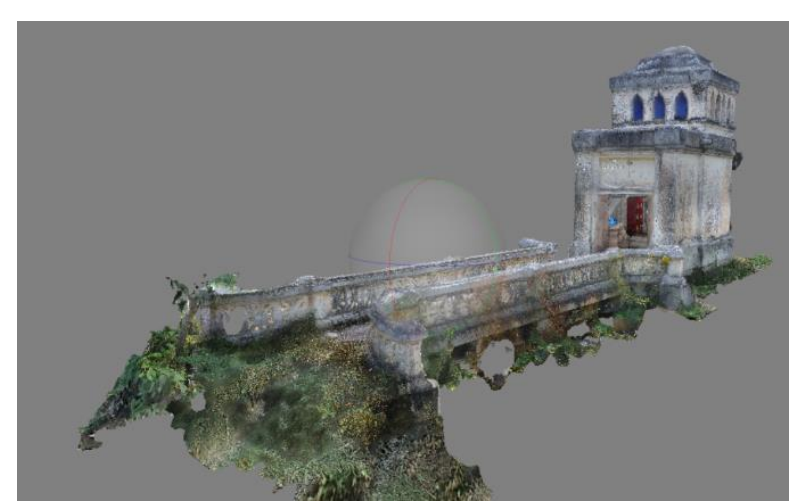

Gambar 12. Hasil Akhir Model 3D Eksterior Mausoleum Dinger

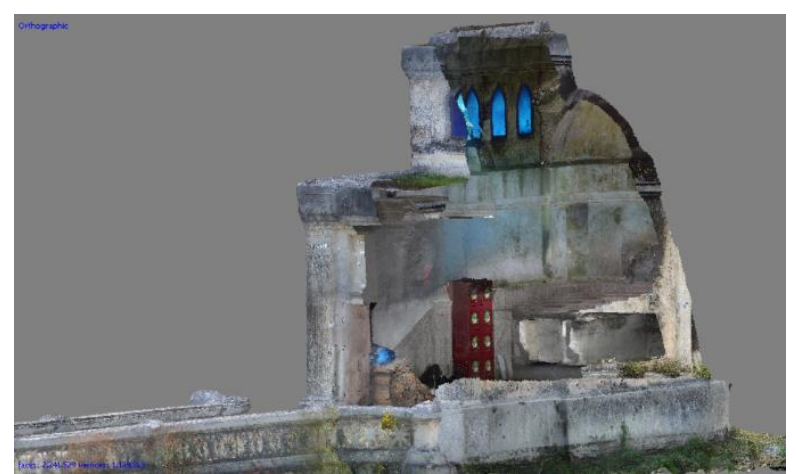

Gambar 13. Hasil Akhir Model 3D Interior Mausoleum Dinger

\section{Analisa}

1. Koordinat $X$

Koordinat $X$ memiliki standar deviasi sebesar $0.026 \mathrm{~m}$. dan nilai RMSE sebesar $0.045 \mathrm{~m}$. Untuk uji error probability pada selang kepercayaan 95\% dimana nilai E95 $=0.051$ selang kepercayaan -0.088 hingga $0.014 \mathrm{~m}$. Pada tabel 7, titik ICP5 dan ICP48 tidak diterima. Sehingga dari 22 data, terdapat 20 data diterima atau $90.91 \%$ dari keseluruhan data.

Tabel 7. Tabel Uji Error Koordinat X

\begin{tabular}{|c|c|c|c|c|c|}
\hline \multirow[b]{2}{*}{ No. } & \multirow{2}{*}{$\begin{array}{c}\text { Nama } \\
\text { Titik }\end{array}$} & \multicolumn{2}{|c|}{$X(m)$} & \multirow{2}{*}{$\begin{array}{c}\text { Error } \\
(\mathrm{m})\end{array}$} & \multirow[b]{2}{*}{ Ket } \\
\hline & & $\begin{array}{c}\text { Pengukuran } \\
\text { Lapangan }\end{array}$ & Model 3D & & \\
\hline 1 & ICP1 & 667834.546 & 667834.501 & -0.045 & Diterima \\
\hline 2 & ICP2 & 667834.54 & 667834.497 & -0.043 & Diterima \\
\hline 3 & ICP4 & 667831.208 & 667831.145 & -0.063 & Diterima \\
\hline 4 & ICP5 & 667831.458 & 667831.359 & -0.099 & $\begin{array}{c}\text { Tidak } \\
\text { diterima }\end{array}$ \\
\hline 5 & ICP6 & 667831.414 & 667831.365 & -0.049 & Diterima \\
\hline 6 & ICP7 & 667834.204 & 667834.163 & -0.041 & Diterima \\
\hline 7 & ICP8 & 667834.212 & 667834.181 & -0.031 & Diterima \\
\hline 8 & ICP9 & 667833.686 & 667833.637 & -0.049 & Diterima \\
\hline
\end{tabular}

\begin{tabular}{cccccc}
9 & ICP11 & 667831.836 & 667831.779 & -0.057 & Diterima \\
10 & ICP18 & 667831.535 & 667831.480 & -0.054 & Diterima \\
11 & ICP19 & 667833.444 & 667833.387 & -0.056 & Diterima \\
12 & ICP24 & 667832.406 & 667832.374 & -0.032 & Diterima \\
13 & ICP30 & 667830.964 & 667830.955 & -0.008 & Diterima \\
14 & ICP31 & 667830.69 & 667830.657 & -0.033 & Diterima \\
15 & ICP35 & 667830.88 & 667830.86 & -0.020 & Diterima \\
16 & ICP47 & 667830.801 & 667830.793 & -0.008 & Diterima \\
17 & ICP48 & 667830.274 & 667830.310 & 0.036 & Didak \\
18 & ICP50 & 667833.719 & 667833.683 & -0.036 & Diterima \\
19 & ICP51 & 667834.113 & 667834.094 & -0.019 & Diterima \\
20 & ICP52 & 667834.063 & 667834.028 & -0.035 & Diterima \\
21 & ICP53 & 667834.334 & 667834.293 & -0.041 & Diterima \\
22 & ICP54 & 667834.062 & 667834.029 & -0.033 & Diterima \\
\hline & & & & &
\end{tabular}

2. Koordinat $Y$

Koordinat $Y$ memiliki standar deviasi sebesar 0.029 m. dan nilai RMSE sebesar 0.028 m. Untuk uji error probability pada selang kepercayaan 95\% dimana nilai $\mathrm{E95}=0.057$ selang kepercayaan -0.060 hingga $0.054 \mathrm{~m}$. Pada tabel 7, titik ICP5 dan ICP48 tidak diterima. Sehingga dari 22 data, terdapat 20 data diterima atau 90.91\% dari keseluruhan data.

Tabel 8. Uji Error Koordinat $Y$

\begin{tabular}{|c|c|c|c|c|c|}
\hline \multirow{2}{*}{ No. } & \multirow{2}{*}{$\begin{array}{l}\text { Nama } \\
\text { Titik }\end{array}$} & \multicolumn{2}{|c|}{$X(m)$} & \multirow{2}{*}{$\begin{array}{c}\text { Error } \\
(\mathrm{m})\end{array}$} & \multirow[t]{2}{*}{ Ket } \\
\hline & & $\begin{array}{c}\text { Pengukuran } \\
\text { Lapangan }\end{array}$ & Model 3D & & \\
\hline 1 & ICP1 & 9137791.232 & 9137791.261 & 0.030 & Diterima \\
\hline 2 & ICP2 & 9137791.245 & 9137791.260 & 0.016 & Diterima \\
\hline 3 & ICP4 & 9137791.68 & 9137791.673 & -0.007 & Diterima \\
\hline 4 & ICP5 & 9137791.331 & 9137791.237 & -0.094 & $\begin{array}{c}\text { Tidak } \\
\text { Diterima }\end{array}$ \\
\hline 5 & ICP6 & 9137791.233 & 9137791.229 & -0.003 & Diterima \\
\hline 6 & ICP7 & 9137790.873 & 9137790.893 & 0.020 & Diterima \\
\hline 7 & ICP8 & 9137790.897 & 9137790.908 & 0.011 & Diterima \\
\hline 8 & ICP9 & 9137790.457 & 9137790.473 & 0.017 & Diterima \\
\hline 9 & ICP11 & 9137790.74 & 9137790.731 & -0.008 & Diterima \\
\hline 10 & ICP18 & 9137788.58 & 9137788.564 & -0.016 & Diterima \\
\hline 11 & ICP19 & 9137788.312 & 9137788.304 & -0.007 & Diterima \\
\hline 12 & ICP24 & 9137787.79 & 9137787.786 & -0.004 & Diterima \\
\hline 13 & ICP30 & 9137788.14 & 9137788.153 & 0.013 & Diterima \\
\hline 14 & ICP31 & 9137787.838 & 9137787.775 & -0.063 & $\begin{array}{c}\text { Tidak } \\
\text { Diterima }\end{array}$ \\
\hline 15 & ICP35 & 9137788.58 & 9137788.594 & 0.015 & Diterima \\
\hline 16 & ICP47 & 9137787.865 & 9137787.864 & -0.001 & Diterima \\
\hline 17 & ICP48 & 9137784.867 & 9137784.879 & 0.013 & Diterima \\
\hline
\end{tabular}




\begin{tabular}{llllll}
18 & ICP50 & 9137784.45 & 9137784.464 & 0.015 & Diterima \\
19 & ICP51 & 9137787.29 & 9137787.31 & 0.020 & Diterima \\
20 & ICP52 & 9137788.167 & 9137788.193 & -0.026 & Diterima \\
21 & ICP53 & 9137790.35 & 9137790.362 & 0.012 & Diterima \\
22 & ICP54 & 9137787.317 & 9137787.337 & -0.020 & Diterima \\
\hline
\end{tabular}

3. Koordinat $Z$

Koordinat $X$ memiliki standar deviasi sebesar $0.035 \mathrm{~m}$. dan nilai RMSE sebesar $0.034 \mathrm{~m}$. Untuk uji error probability pada selang kepercayaan 95\% dimana nilai E95 $=0.069$ selang kepercayaan -0.073 hingga $0.065 \mathrm{~m}$. Pada tabel 7, titik ICP5 dan ICP48 tidak diterima. Sehingga dari 22 data, terdapat 21 data diterima atau $95.45 \%$ dari keseluruhan data.

Tabel 9. Uji Error Koordinat Z

\begin{tabular}{cccccc}
\hline \multirow{2}{*}{ No. } & \multirow{2}{*}{ Nama } & \multicolumn{2}{c}{$Z(\mathrm{~m})$} & Error & Ket \\
\cline { 3 - 5 } & Titik & $\begin{array}{c}\text { Pengukura } \\
\text { n Lapangan }\end{array}$ & $\begin{array}{c}\text { Model } \\
\text { 3D }\end{array}$ & $(\mathrm{m})$ & \\
\hline 1 & ICP1 & 1356.509 & 1356.531 & 0.022 & Diterima \\
2 & ICP2 & 1356.848 & 1356.880 & 0.032 & Diterima \\
3 & ICP4 & 1356.479 & 1356.489 & 0.010 & Diterima \\
4 & ICP5 & 1356.918 & 1356.856 & -0.061 & Diterima \\
5 & ICP6 & 1357.054 & 1357.081 & 0.028 & Diterima \\
6 & ICP7 & 1357.093 & 1357.120 & 0.027 & Diterima \\
7 & ICP8 & 1356.96 & 1356.870 & -0.090 & Tidak \\
8 & ICP9 & 1357.554 & 1357.580 & 0.026 & Diterima \\
9 & ICP11 & 1357.542 & 1357.567 & 0.025 & Diterima \\
10 & ICP18 & 1357.544 & 1357.544 & -0.001 & Diterima \\
11 & ICP19 & 1357.554 & 1357.568 & 0.014 & Diterima \\
12 & ICP24 & 1356.281 & 1356.258 & -0.023 & Diterima \\
13 & ICP30 & 1357.085 & 1357.073 & -0.012 & Diterima \\
14 & ICP31 & 1356.876 & 1356.882 & -0.054 & Diterima \\
15 & ICP35 & 1356.267 & 1356.232 & -0.034 & Diterima \\
16 & ICP47 & 1354.864 & 1354.872 & 0.008 & Diterima \\
17 & ICP48 & 1354.765 & 1354.719 & -0.046 & Diterima \\
18 & ICP50 & 1354.704 & 1354.753 & 0.049 & Diterima \\
19 & ICP51 & 1354.789 & 1354.794 & 0.005 & Diterima \\
20 & ICP52 & 1356.293 & 1356.284 & -0.009 & Diterima \\
21 & ICP53 & 1356.279 & 1356.274 & -0.005 & Diterima \\
22 & ICP54 & 1356.862 & 1356.869 & 0.008 & Diterima \\
\hline & & & & &
\end{tabular}

4. Panjang

Pada penelitian ini dilakukan perbandingan panjang yang diperoleh dari pengukuran lapangan menggunakan roll meter dengan panjang Model 3D yang terbentuk.

Tabel 10. Perbandingan Panjang

\begin{tabular}{|c|c|c|c|c|}
\hline \multirow[b]{2}{*}{ No. } & \multirow[b]{2}{*}{ Nama Titik } & \multicolumn{2}{|c|}{ Panjang (m) } & \multirow{2}{*}{$\begin{array}{c}\text { Error } \\
(\mathrm{m})\end{array}$} \\
\hline & & $\begin{array}{c}\text { Pengukuran } \\
\text { lapangan }\end{array}$ & $\begin{array}{c}\text { Model } \\
3 \mathrm{D}\end{array}$ & \\
\hline 1 & $\begin{array}{c}\text { Panjang Struktur } \\
\text { Jembatan }\end{array}$ & 9.84 & 9.72 & -0.12 \\
\hline 2 & $\begin{array}{c}\text { Lebar Struktur } \\
\text { Jembatan }\end{array}$ & 1.70 & 1.59 & -0.11 \\
\hline 3 & $\begin{array}{c}\text { Panjang } \\
\text { Bangunan Utama }\end{array}$ & 6.84 & 6.67 & -0.17 \\
\hline
\end{tabular}

\section{KESIMPULAN}

Pada penelitian ini, kesimpulan yang dapat diambil adalah sebagai berikut:

1.Telah dilakukan proses akuisisi data guna pembuatan model 3D menggunakan metode fotogrametri jarak dekat yang menghasilkan total 829 foto baik dari sisi interior maupun eksterior.

2.Dihasilkan model 3D Mausoleum Dinger dengan menggunakan metode fotogrametri jarak dekat baik sisi ekstrior maupun interior yang terbentuk dari 814 foto dan terdiri dari 291.313 titik sparse cloud, 48.908.115 titik dense cloud, dan 3.242.572 faces.

3. Model 3d berdasarkan nilai total RMSE dan juga terbentuknya model interior objek telah memenuhi kriteria LoD 4. Adapun untuk nilai RMSE $0.2 \mathrm{~m}$. Berikut nilai RMSE koordinat model 3D

- Koordinat $X$ dengan RMSEX $=0.045 \mathrm{~m}$

- Koordinat $Y$ dengan RMSEY $=0.028 \mathrm{~m}$

- Koordinat $Z$ dengan RMSEZ $=0.048 \mathrm{~m}$

\section{UCAPAN TERIMA KASIH}

Penulis D.A.F. mengucapkan terimakasih kepada Pemerintah Kota Batu dalam hal ini yaitu Dinas Pariwisata yang telah memberikan ijin dan dukungan untuk penelitian ini.

\section{DAFTAR PUSTAKA}

Mikhail, Bethel, and McGlone 2001: Edward M. Mikhail, James S. Bethel, J. Chris McGlone. Introduction to Modern Photogrammetry (Wiley).

Pemerintah Indonesia. 2010. Undang-undang Nomor 11 Tahun 2010 tentang Cagar Budaya. Lembaran 
Negara RI Tahun 2010, No.130. Sekretariat Negara. Jakarta.

Permana, R.W. 2016. Makam Dinger, Kuburan Tak Bertuan Peninggalan Meneer Belanda. Diperoleh 16 Juni 2019, dari https://malang.merdeka.com/pariwi sata/makam-dinger-kuburan-tak-bertuanpeninggalan -meneer-belanda-161116d.html.

Rashidi, A., Dai, F., Brilakis, I. \& Vella, P., 2013. Optimized Selection of Key Frames for Monocular Videogrammetric Surveying of Civil Infrastructure. Elsevier, pp. 270-282.

Stone, W., \& Cheok, G. 2001. LADAR Sensing Applications for Construction. 